\title{
Control of E-S Potentiation at two different sites in the dendro-somatic axis
}

Short title: Control of E-S potentiation

\section{Jason K. Clark and Daniel V. Madison}

Department of Molecular \& Cellular Physiology, Stanford University School of Medicine. Stanford, California, USA 94305-5345

Corresponding Author: DV Madison; madison@stanford.edu

Number of pages: 51 (including figures, legends and references, 25 without) Number of figures: 6

Number of words: abstract: 249, introduction: 601, discussion: 1416

Acknowledgments: Funding for this work was provided by a grant from the National Institute of Mental Health (MH111768) and by the Harold and Leila Y. Mathers

Charitable Foundation. We thank Sonja Winter from the Department of Psychological

Sciences at UC Merced for helpful discussion about the use of statistics, and members of the Madison Lab for useful discussion on the experiments and manuscript.

The authors declare no competing financial interests. 


\section{Abstract}

3 EPSP-Spike (E-S) Potentiation occurs alongside synaptic Long-Term Potentiation

4 (LTP), both triggered by high-frequency synaptic stimulation (HFS). In this study, we

5 confirm the earlier findings that E-S potentiation appears to be prevented by prior

6 reduction of $\mathrm{GABA}_{A}$ receptor-mediated inhibitory synaptic transmission. However, we

7 demonstrate that this is a result of an occlusion of E-S potentiation, not a block. E-S

8 potentiation and $\mathrm{GABA}_{\mathrm{A}}$ antagonism each saturate postsynaptic action potential

9 discharge, but E-S potentiation can still be induced by high frequency activation of

10 synapses, even in the presence of pharmacological GABAA blockade. These results

11 suggest that $\mathrm{GABA}_{\mathrm{A}}$ blockers/antagonists and E-S potentiation share an expression

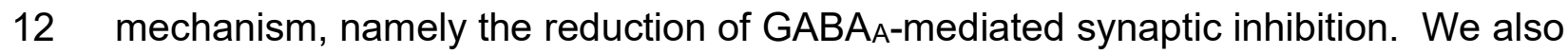

13 assayed changes in the electrical coupling between dendrite and soma, and were

14 surprised to find that this coupling is decreased following HFS, a change that would

15 oppose E-S potentiation. This decrease in dendritic-soma electrical coupling (D-S

16 coupling) was induced through the action of GABA $A_{B}$ receptors, but not maintained or

17 expressed via the activity of these receptors. These data all together suggest that there

18 are two distinct and opposing changes that occur as a result of HFS: 1) A decrease in

19 passive dendro-somatic electrical coupling, and 2), an increase in coupling between the

20 somatic EPSP and action potential generation. These two opposing influences may

21 function as a homeostatic mechanism to balance the excitatory/inhibitory relationship

22 between primary neurons and interneurons, and may represent a separate mechanism 
23 by which feedback and feed-forward synaptic inhibition can influence E-S coupling in 24 opposite directions.

27 KEY WORDS: EPSP-Spike Potentiation; Dendro-Somatic Coupling; GABAB; Intrinsic Plasticity; Picrotoxin; CGP-54626

30 Significance statement: E-S Potentiation is an activity-dependent form of plasticity

31 that boosts the efficiency of the coupling between synaptic input and action potential

32 output in a neuron. Because it is induced by synaptic activity in series with the more

33 familiar long-term potentiation (LTP), and is similarly persistent, it represents an

34 additional mechanism by which memory traces may be stored within neural circuits.

35 The significance of this paper is that it shows that there are at least two points of

36 control for E-S potentiation which influence it in opposite directions, thereby providing

37 additional basic mechanisms by which memory traces may be modulated.

38 


\section{Introduction}

42 High frequency activation of the Schaffer collaterals in Area CA1 of

43 hippocampus, and other excitatory synapses in the hippocampal formation, results in

44 the induction of at least two parallel types of synaptic potentiation: Long-Term

45 Potentiation (LTP) of the Excitatory Post-Synaptic Potential (EPSP); and EPSP-Spike

46 potentiation (E-S potentiation), the increase in postsynaptic action potential discharge

47 for a given EPSP magnitude. That both LTP and E-S potentiation are induced

48 simultaneously by the same high frequency activation of synapses was recognized in

49 the earliest reports of LTP [1], although later reports have shown that it may be possible

50 to induce them separately $[2,3]$.

Three broad mechanisms might account for the expression of E-S potentiation:

53 1) A decrease in GABA-mediated synaptic inhibition, which would act to decrease

54 shunting of EPSP current at dendritic and/or somatic membrane on its way to the spike

55 trigger zone at the axon hillock; 2) An increase in the electrotonic coupling between

56 dendrite and soma; and 3) A change in the postsynaptic action potential threshold to

57 more hyperpolarized voltages, which has been reported [4, 5], although this might be an

58 indirect effect related to changes in synaptic inhibition. The other two mechanisms

59 differ in whether they reflect a change in inhibitory neurotransmission, or are a cell-

60 autonomous property of pyramidal neurons [6]. Previous studies have examined the

61 role of dendritic electrical properties during production of E-S potentiation, but the

62 conclusions have been inconsistent $[7,8]$. 
E-S potentiation is generally thought to result at least in part from a reduction in

65 GABAergic signaling. GABAA antagonists appear to prevent the development of E-S

66 potentiation [5, 6, 9-12]. Application of the GABAA channel blocker Picrotoxin (PTX)

67 before High Frequency Stimulation (HFS) potentiates the population spike signal,

68 mimicking E-S potentiation, and this PTX enhancement is at least reduced by prior HFS

69 [9]. Intracellular recordings show a decrease in the IPSP after tetanus that is blocked

70 by application of the NMDA receptor antagonist AP5, and is Calcineurin dependent [12],

71 but others show no significant change in IPSPs [13]. The induction of E-S potentiation,

72 like LTP, seems to depend on the NMDA receptor, but it is not clear if these are the

73 same populations of NMDA receptors for both plasticities. E-S potentiation may also be

74 mediated by a long-term depression of synapses onto interneurons from pyramidal

75 neurons [14]. In earlier studies, this was attributed to a decrease in feed-forward in

76 inhibition, though feedback inhibition is more widely viewed as being mediated by

77 GABAA transmission, as opposed to a dominant role of GABAB transmission in feed-

78 forward inhibition $[9,15,16]$. The second major hypothesis for the development of E-S

79 potentiation has involved potentially cell-autonomous mechanisms, such as changes in

80 the intrinsic excitability or dendritic membrane resistance [4, 17-21].

In this study, we aim to explore the hypothesis that changes in inhibitory control

83 contribute to the development of E-S potentiation and/or whether non-inhibition-related

84 changes in electrotonic coupling might also participate. We find that blockade of

$85 \mathrm{GABA}_{\mathrm{A}}$ transmission occludes the expression of E-S potentiation, but not its induction.

86 This occlusion occurs in both directions: prior application of a $\mathrm{GABA}_{A}$ blocker prevents 
87 HFS-induced increases in E-S coupling, and prior HFS prevents increases in coupling

88 by application of a GABAA blocker. But to our surprise, tetanic stimulation decreases

89 the electrical coupling between dendrite and soma, a change that is in opposition to the

90 production of E-S potentiation. This change is triggered by $\mathrm{GABA}_{\mathrm{B}}$ transmission, and

91 demonstrates a previously unreported form of $G A B A_{B}$ receptor-mediated intrinsic

92 plasticity. These opposing effects may function as independent regulators of

93 information processing or memory trace storage at the level of both the individual

94 neuron, and the hippocampal micro-circuitry.

95

96 Materials and Methods

$97 \quad$ Animals and euthanasia

98

All animals used in this study were male Sprague-Dawley rats approximately 6

99 weeks old, obtained from Charles River Laboratories (Wilmington, MA). Animals were

100 housed at Stanford University in an AAALAC accredited facility on a 12 hour light/dark

101 timed scheduled with ad libitum access to food and water. Euthanasia of animals

102 occurred under deep anesthesia with isoflurane followed by decapitation. All

103 procedures were performed in strict compliance with a protocol approved by The

104 Stanford University Animal Care and Use Committee.

105

106 Chemicals and reagents

107 Except where noted, specialty chemicals were obtained from Sigma Aldrich (St.

108 Louis, MO) or Tocris Biosciences (Minneapolis, MN). 


\section{Extracellular field potential recording}

111 Hippocampal slices were prepared from male wild-type Sprague-Dawley rats

112 approximately 6 weeks old. Rats were deeply anesthetized with isoflurane prior to

113 decapitation. The brain was removed and submerged in ice-cold, oxygenated $\left(95 \% \mathrm{O}_{2} /\right.$

$1145 \% \mathrm{CO}_{2}$ ) dissection artificial cerebrospinal fluid (dACSF) containing: $\mathrm{NaCl}(119 \mathrm{mM})$,

$115 \mathrm{KCl}(2.5 \mathrm{mM}), \mathrm{MgCl}_{2}(3.8 \mathrm{mM}), \mathrm{NaH}_{2} \mathrm{PO}_{4}(1.0 \mathrm{mM}), \mathrm{NaHCO}_{3}(26.2 \mathrm{mM})$, and D-Glucose

$116(11 \mathrm{mM})$. The brain was sectioned using a Vibratome through the horizontal plane into

$117500 \mu \mathrm{m}$ thick slices. The hippocampus was then dissected free from slices and the CA3

118 region was removed. We estimate such slices were from the middle $30 \%$ of the

119 hippocampus with respect to the longitudinal axis. We excluded slices from the extreme

120 dorsal and ventral poles. Slices were placed in a submersion recording chamber

121 (Harvard Apparatus, Holliston, MA) and perfused at approximately $100 \mathrm{ml} / \mathrm{hr}(1.67$

$122 \mathrm{ml} / \mathrm{min}$, Gilson miniplus 2 peristaltic pump) with oxygenated $\left(95 \% \mathrm{O}_{2} / 5 \% \mathrm{CO}_{2}\right)$

123 standard ACSF containing: $\mathrm{NaCl}(119 \mathrm{mM}), \mathrm{KCl}(2.5 \mathrm{mM}), \mathrm{MgCl}_{2}(1.3 \mathrm{mM}), \mathrm{CaCl}_{2}(2.5$

$124 \mathrm{mM}), \mathrm{NaH}_{2} \mathrm{PO}_{4}(1.0 \mathrm{mM}), \mathrm{NaHCO}_{3}(26.2 \mathrm{mM})$, and D-Glucose (11 mM). Slices

125 recovered for 30 minutes at room temperature and an additional 120 minutes at $30^{\circ} \mathrm{C}$.

126 A bipolar stimulating electrode (FHC, Inc., Bowdoin, ME) was placed within the stratum

127 radiatum of CA1, and two glass capillary extracellular recording microelectrodes filled

128 with $3 \mathrm{M} \mathrm{NaCl}$ (pulled on a Sutter Instruments P-87 Brown flaming microelectrode puller

129 to a resistance of approximately $5 \mathrm{M} \Omega$ ) were placed within the hippocampal slice with

130 one in the stratum radiatum layer of $\mathrm{CA} 1$, and the other in the stratum pyramidal layer of

131 CA1. Both recording electrodes were placed in the same horizontal plane with each

132 electrode tip aligned to the same imaginary longitudinal y-axis. Synaptic field Excitatory 
133 Post-Synaptic Potentials (fEPSPs) and simultaneously recorded somatic field

134 population spikes were recorded in response to stimulation of Schaffer collateral $\rightarrow \mathrm{CA} 1$

135 synapses using a stimulus pulse consisting of a single square wave of $100 \mu$ s duration.

136 Data were collected and digitized at $10 \mathrm{kHz}$, low-pass filtered at $1 \mathrm{kHz}$, and analyzed

137 with pCLAMP 11.0 (Molecular Devices, San Jose, CA) or by lab-written software under

138 LabVIEW 7.1 (National Instruments, Austin, TX). The initial slope of the synaptic fEPSP

139 was measured by fitting a straight line to a $1 \mathrm{~ms}$ window to the initial slope of the

140 fEPSP. The slope of the somatic fEPSP was measured by fitting a straight line to a 1

141 ms window immediately prior to the onset of the population spike. The area of the

142 population spike was measured by creating an imaginary line from the spike onset to

143 the spike termination and capturing the area within the spike under the imaginary border

144 (see Fig 1A). Area was measured instead of amplitude as an index of total neuron firing

145 without regard to differences in synchronicity.

Stimulus response (Input/Output) curves were obtained at the beginning and end

148 of each experiment, and at specific time points within an experiment when appropriate

149 as indicated for each figure. Stimulus pulses were delivered at 10, 20, 30, 40, 60, 80,

$150100,120,140,160,180,200,220,240,260,280$, and $300 \mu \mathrm{A}$ at $0.033 \mathrm{~Hz}$ (once every

$15130 \mathrm{~s}$ ). Initial conditions were set such that the population spike to dendritic fEPSP ratio

152 was $3: 1$, to maintain dynamic range for the population spike, particularly below

153 saturation. Long-Term Potentiation (LTP) experiments were carried out with a baseline

154 stimulus delivered at $0.0167 \mathrm{~Hz}$ (once every $60 \mathrm{~s}$ ) and normalized by dividing all

155 synaptic fEPSP slope values or population spike area values by the average of the 5 
156 responses recorded during the 5 minutes immediately prior to High Frequency

157 Stimulation (HFS). LTP was induced by subjecting the slice to HFS consisting of 3

158 episodes of $100 \mathrm{~Hz}$ for $1 \mathrm{~s}$ stimulus trains (100 pulses x3) administered at $20 \mathrm{~s}$ inter-

159 train intervals. Values indicating drug response were normalized to the 5 minutes of

160 responses immediately prior to drug application, and were determined by averaging 5

161 minutes of normalized values at specific time points after drug application as indicated

162 for each figure.

Due to the dynamic nature of E-S potentiation, quantification was estimated by

165 determining the difference in population spike area before and after HFS with input

166 matched dendritic EPSPs (i.e., we compared population spikes with an fEPSP slope of

$167 \sim 0.7 \mathrm{mV} / \mathrm{ms}$ before HFS, to population spikes with an fEPSP slope of $\sim 0.7 \mathrm{mV} / \mathrm{ms}$ after

168 HFS). Data used for this analysis was obtained from Input/Output curve data.

169

170 In order to evaluate the contribution of GABAergic signaling on LTP and E-S

171 potentiation, the $\mathrm{GABA}_{A}$ channel blocker Picrotoxin $(50 \mu \mathrm{M})$ or the $\mathrm{GABA}_{B}$ antagonist

172 CGP-54626 (3 $\mu \mathrm{M})$ (Tocris Bioscience, Minneapolis, MN) was bath applied 80 min prior

173 to HFS. In experiments where Picrotoxin or CGP-54626 was applied after LTP

174 induction, it was bath applied 15 min post-HFS as not to interfere with any post-tetanic

175 potentiation mechanisms. In experiments where Picrotoxin was washed out after LTP

176 induction, washout began 5 minutes post-HFS. 
179 Experimental Design and Statistical Analysis

180 Sample size was calculated with an expectation of being able to detect changes

181 of $20 \%$ or more in measurements. Given the typical standard deviation of similar

182 experiments, a power of 0.9 , and an alpha cutoff of 0.05 , this would require a sample

183 size of approximately 8. Tests of significance were performed using a One-way ANOVA

184 with Tukey's post-hoc analysis for comparison of HFS induced potentiation of the

185 dendritic EPSP slope, somatic EPSP slope, and population spike area across treatment

186 groups. Analysis of the effect of drug application on recordings within a specific

187 treatment group was performed using a paired t-Test. Data pertaining to the dendritic

188 EPSP slope, somatic EPSP slope, and population spike area generated from input

189 matched traces before and after HFS, and used to construct bar graph data, were

190 compared using independent t-Test for each treatment group. Statistical analysis was

191 performed with SYSTAT 13 software (San Jose, CA). Reported n-values indicate the

192 number of slices and animals assessed (one slice/animal).

193

194

195

196 


\section{Results}

Electrophysiological recordings of extracellular field potentials were obtained by stimulation of the Schaffer collateral axons and recording of both the dendritic EPSP

200 field in the s. radiatum and the resulting simultaneously recorded population spike field 201 in the s. pyramidal layer, in the CA1 region of mid hippocampus (Figure 1A). In each

202 experiment, LTP and E-S potentiation were induced simultaneously with the same High 203 Frequency Stimulation (HFS: $100 \mathrm{~Hz}$ for $1 \mathrm{sec}$ tetanic stimulation x3). We performed

204 experiments designed to test whether the GABAA open channel blocker Picrotoxin 205 (PTX) prevented the induction of E-S potentiation by applying HFS in the presence or 206 absence of PTX $(50 \mu \mathrm{M})$ under the following three conditions: 1) No Drug (control, no 207 PTX), 2) PTX bath-applied throughout the experiment (PTX), and 3) PTX applied 208 beginning 15 min after HFS (PTX post-HFS) (Figure 1B). In every experiment we 209 conducted an Input/Output $(\mathrm{I} / \mathrm{O})$ curve at the beginning and end of each experiment to 210 determine the relationship between the EPSP and action potential generation

211 (population spike) before and after the induction of potentiation by HFS (Figure 1B and 212 1C). HFS induced potentiation of both the dendritic EPSP (Figure 1.B1) and the 213 population spike (Figure 1.B2) in all three conditions. Results showed LTP of the 214 dendritic EPSP in both the PTX $(n=12)$ and PTX post-HFS $(n=10)$ groups was not 215 different than the No Drug control $(n=12)$. LTP of the population spike however, was 216 reduced when PTX was applied throughout the experiment compared to control, but 217 had no effect on the population spike when applied after HFS, which was similar to 218 control (No Drug: $93 \pm$ 15\%; PTX: $33 \pm 5 \%$; PTX post-HFS: $97 \pm$ 19\%)(ANOVA, $219 F(2,31)=7.38, p<0.01)$. As expected, the $\mathrm{I} / \mathrm{O}$ curves in all three conditions for both the 
220 dendritic EPSP field and the population spike were elevated at the end of the

221 experiment after HFS, compared to the I/O curves at the beginning of the experiment

222 before HFS (Figure 1C). Note that the I/O curves of both the EPSP field and population

223 spike in appear on the same graph.

Data from the I/O curves in Figure $1 \mathrm{C}$ was used to construct E-S coupling curves

226 for each of the three conditions. These curves were constructed by plotting the slope of

227 the dendritic EPSP against the area of the population spike to show the relationship

228 between synaptic input and spike output throughout a range of synaptic responses

229 (Figure 2). In the absence of drug, HFS results in a persistent leftward shift in the E-S

230 coupling curve, indicative that E-S potentiation has occurred (Figure 2.A1). When PTX

231 was present throughout the experiment however, HFS produced no shift in the E-S

232 coupling curve, indicating no change in E-S coupling and no E-S potentiation in this

233 condition (Figure 2.B1), consistent with previously published results that blockade of

$234 \mathrm{GABA}_{A}$ transmission blocks E-S potentiation [9]. However, we found that if PTX was

235 applied after the induction of potentiation (post-HFS), that this produced only a minimal

236 enhancement of that shift (Figure 2.C1). These results suggest one of two possibilities:

237 1) That PTX present during induction blocks the induction of E-S potentiation, or 2) PTX

238 causes a change in the relationship between the EPSP and population spike that

239 occludes the expression of E-S potentiation.

241 While LTP can be observed directly as the increase in both the dendritic EPSP

242 and population spike, E-S potentiation is most clearly seen in the leftward shift of the E- 
243 S coupling curves, where it is clear that a given sized EPSP produces a greater

244 population spike after HFS. E-S potentiation can also be observed in a second manner,

245 by turning down the stimulus strength post HFS, to produce a dendritic EPSP field that

246 matches the magnitude of the pre-HFS dendritic field. These input matched traces

247 appear in Figures 2.A2, B2 and C2. The inset bar graphs show averaged values for

248 EPSP slope and population spike area corresponding to the averaged traces shown

249 above. Despite the reduced stimulus strength, matched dendritic EPSPs after HFS

250 generate greater population spikes compared to matched dendritic EPSPs before HFS

251 in both the No Drug control (Figure 2.A2; t-Test, $\mathrm{p}<0.01$ ), and when PTX is applied

252 post-HFS (Figure 2.C2; t-Test, $\mathrm{p}<0.01$ ), showing that a given sized EPSP produces a

253 greater spike output from that population of pyramidal neurons; i.e., E-S potentiation

254 occurred. This is not seen however, when PTX is present throughout the experiment

255 (Figure 2.B2; t-Test, $p=0.48$ ), consistent with the E-S coupling curve in Figure 2.B1.

Upon closer inspection, we observed that the presence of PTX prior to HFS

258 seemed to produce a population spike that was similar in magnitude to the population

259 spikes after induction seen in the No Drug control and PTX post-HFS groups. In

260 addition, the E-S coupling curve prior to HFS seen when PTX was present throughout

261 the experiment (Figure 2.B1) was more similar to the leftward-shifted curves caused by

262 HFS in the No Drug control and PTX post-HFS groups, than to the baseline non-shifted

263 curves in those groups. This suggested that the effect of PTX may not actually prevent

264 E-S potentiation, but rather occlude it, by pre-saturating the population spike through an

265 increase in firing secondary to a reduction of GABAA-mediated synaptic transmission. 
266 To differentiate between block or occlusion of E-S potentiation by PTX, we performed

267 experiments to determine whether E-S potentiation could still be induced by HFS in the

268 presence of PTX, even if its expression was occluded. We carried out this test by

269 applying PTX to baseline recordings, then either applying HFS for induction, or not,

270 before subsequently washing PTX from the slice. If the population spike remained

271 elevated after washout of PTX, then E-S potentiation was induced, but if the population

272 spike returned to baseline, then it was not (Figure 3). We conducted I/O curves at three

273 different time points throughout the experiment: At the beginning, after the application of

274 PTX but before the induction of potentiation with HFS, and at the end of each

275 experiment after PTX washout. E-S coupling curves were constructed from these data

276 in the same manner as in Figure 2.

In the absence of PTX, both the dendritic EPSP (Figure 3.A1) and population

279 spike (Figure 3.A2) potentiated with HFS as expected. The first and second I/O curves

280 are both pre-HFS, and the corresponding E-S coupling curves for these time points are

281 similar, indicating a stable relationship between the dendritic EPSP and population

282 spike (Figure 3.C1). After induction, the persistent leftward shift in the third curve shows

283 that E-S potentiation was stable for at least three hours post-HFS (Figure 3.C1, open

284 symbols). For comparison, when no HFS was performed, and in the absence of PTX,

285 the E-S relationship was stable over the entire five hour recording period, as shown by

286 the three identical E-S coupling curves at all three time points (Figure 3.C2). 
The application of PTX to baseline recordings had various effects on the dendritic EPSP and population spike (Figure 3B). Application of PTX caused a very small

290 increase in the dendritic EPSP $(16 \pm 4 \%$; paired t-Test, $p<0.01)$ that could then be

291 further significantly potentiated with HFS (paired t-Test, $p<0.01$ ) (Figure 3.B1). Upon

292 PTX washout, LTP was not different than LTP in the No Drug control (No Drug: $59 \pm$

$29310 \%, n=9$; PTX-WO: $56 \pm 7 \%, n=10$ ). The population spike however, showed a

294 substantial increase after PTX application ( $81 \pm 14 \%$; paired t-Test, $p<0.01)$ that could

295 not be further significantly potentiated with HFS (Figure 3.B2). Upon PTX washout, the

296 population spike remained potentiated at a level similar to that seen before HFS, and

297 also at a level similar to that seen in the potentiated No Drug control (No Drug: $121 \pm$

298 7\%; PTX-WO: $122 \pm 13 \%$ ). The resulting effect on E-S coupling from the application of

299 PTX only can be seen by the leftward shift in the E-S coupling curve in the presence of

300 PTX, but before HFS (Figure 3.D1, red vs. black symbols), and the emergence and

301 persistence of E-S potentiation by the sustained leftward shift in the E-S coupling curve

302 when PTX is washed out after HFS (Figure 3.D1, open symbols). In experiments in

303 which no HFS was performed, and only PTX was applied, the observed increases in the

304 dendritic EPSP and population spike could both be reversed to pre-drug levels upon

305 PTX washout (EPSP: $-6 \pm 6 \%$; PS: $6 \pm 12 \%, n=9$ ), and the resulting shift in the E-S

306 coupling curve from PTX application (Figure 3.D2, red symbols) could also be reversed

307 to a near pre-drug state upon PTX washout (Figure 3.D2, open symbols).

308

These results demonstrate that PTX mimics the expression of, but does not

310 induce, E-S potentiation, and furthermore, that GABAA blockade by PTX does not 
311 prevent the induction E-S potentiation by HFS. E-S potentiation can still be induced by

312 HFS even in the presence of PTX, even though it is not visible in the presence of PTX.

313 Thus, taken together, the experiments in Figures 1-3 show that blockade of GABAA

314 transmission does not block, but merely occludes, E-S potentiation.

316 The two most likely places where coupling between the dendritic EPSP and the

317 somatic action potential can change are in the dendrite itself, between the synapses

318 and the soma, and between the soma and spike trigger zone at the axon hillock, where

319 synaptic inhibition may be the most influential. To isolate the electrotonic coupling

320 between dendrite and soma, we compared measurements of the dendritic EPSP field

321 with measurements of the EPSP field that appears at the soma, i.e., the initial rising

322 slope immediately prior to the downward deflection of the population spike (see Figure

$3231 \mathrm{~A})$. This somatic EPSP represents the passive current source that is secondary to the

324 active current sink driven by the dendritic synapses. It represents the amount of EPSP

325 current that survives transit from the dendritic origin to the soma, and provides a way to

326 measure dendro-somatic electrical coupling (D-S coupling), and has been used

327 previously by others for similar analyses [5, 6, 15, 22, 23].

328

To determine if a change in D-S coupling does occur, and what the potential role

330 of that change might play in the expression of E-S potentiation, we compared LTP of the

331 dendritic EPSP field with that of the somatic EPSP field in the same conditions

332 previously discussed: No Drug, PTX throughout, and PTX post-HFS (Figure 4).

333 Potentiation of the dendritic EPSP shown here (Figure 4.A1) is the same as that shown 
334 in Figure 1.B1, and displayed again here for comparison. The somatic EPSP in all three

335 conditions showed potentiation in response to HFS that was not different across

336 conditions, but was overall proportionally less than potentiation of the dendritic EPSP.

339 earlier figures, by plotting the slope of the dendritic EPSP field potential against the

340 slope of the somatic EPSP field potential across the full range of tested stimulus

341 strengths. This shows the relationship between the dendritic synaptic input current and

342 the amount of that current that reaches the soma, across a range of synaptic responses

343 (Figure 4B-4D). The induction of LTP did, in fact, change the electrical coupling

344 between dendrite and soma, but to our surprise, not in the expected direction. Instead

345 of an increase in coupling, which would have been represented by a leftward shift in the

346 coupling curve, we observed a rightward shift, indicating that the electrical coupling

347 between dendrite and soma was reduced after the induction of LTP. This reduction

348 occurred in the presence or absence of PTX, regardless of when it was applied (Figure

349 4.B1, C1, and D1). The averaged input matched traces shown here in Figure 4.B2, C2,

350 and D2 are the same as those shown in Figure 2, with the somatic EPSP region boxed

351 and magnified, and the addition of the respective somatic EPSP slopes from these

352 traces quantified in the inset bar graphs below. The input matched dendritic EPSP

353 traces clearly show a reduced resultant somatic EPSP after HFS in all three conditions,

354 indicating a reduction in D-S coupling. This reduction is significant in all three

355 conditions, even when PTX was present throughout and E-S potentiation was occluded

356 (t-Test; No Drug: $p<0.01$; PTX: $p<0.05$, PTX post-HFS: $p<0.01$ ). If PTX was absent 
357 during HFS, there was still a significant potentiation of the population spike afterwards,

358 despite there being significantly less surviving current to the soma (Figure 4.B2 and

359 D2). The averaged input matched traces shown in Figures 2, 4, and 5 represent a

360 range of responses that demonstrate both the expression of E-S potentiation and the

361 reduction in D-S coupling. Thus, our initial hypothesis that there would be an increase

362 in electrotonic coupling was incorrect. This result shows there is a GABAA-independent

363 influence in the dendrites of pyramidal neurons that is acting in opposition to E-S

364 potentiation, in that the somatic EPSP is increased by LTP less than might be expected,

365 due to the reduction in Dendro-Somatic coupling.

One possible mediator for this unexpected change in electrical coupling between

368 dendrite and soma might be related to another form of synaptic inhibition, GABA

369 receptor-mediated activity. GABAA receptor density is greatest in the peri-somatic

370 region, while $\mathrm{GABA}_{\mathrm{B}}$ receptor density is more uniform, but greater in distal dendrites,

371 and highest in the s. radiatum, where Schaffer collateral synapses terminate on CA1

372 pyramidal neurons $[16,24,25]$. To test the hypothesis that $\mathrm{GABA}_{\mathrm{B}}-\mathrm{mediated}$

373 transmission was involved in the observed change in D-S coupling after HFS, we

374 examined LTP, E-S coupling, and D-S coupling in the presence of the GABA ${ }_{B}$ receptor

375 antagonist CGP-54626 (CGP). Experiments were performed that were identical to

376 those carried out using PTX as shown in Figures 1, 2, and 4, with the use of CGP (3

$377 \mu \mathrm{M}$ ) in place of PTX (No Drug, $n=12$; CGP throughout, $n=10 ;$ CGP post-HFS, $n=10$ )

378 (Figure 5). The No Drug control data used for comparison with CGP experiments is the

379 same as that used with PTX experiments. Application of CGP did not have any 
380 detectable effect on the baseline coupling between the dendritic and somatic EPSP

381 fields (D-S coupling), or dendritic EPSP and population spike fields (E-S coupling). LTP

382 of the dendritic EPSP and population spike were not different across groups.

383

384 The effects of HFS on E-S coupling and D-S coupling in the presence of CGP

385 were very different than that seen with PTX (Figure 5). When CGP was present during

386 the induction of potentiation (HFS), the rightward shift in the D-S coupling curve was

387 abolished (Figure 5.B2), but the leftward shift in the E-S coupling curve persisted

388 (Figure 5.B1). The input matched traces when CGP was present throughout the

389 experiment reflect these results (Figure 5.B3). One idea that may explain the rightward

390 shift in D-S coupling observed in the control might be that GABA - -mediated inhibitory

391 synaptic transmission is persistently enhanced after LTP induction, however when CGP

392 was applied after induction, it did not reverse the rightward shift (Figure 5.C2), and both

393 the E-S and D-S coupling curves remained shifted similar to that of the control (Figure

$3945 \mathrm{~A}$ vs $5 \mathrm{C})$. The input matched traces visually confirm that after HFS, there is in fact less

395 surviving somatic EPSP (t-Test, $\mathrm{p}<0.05$ ), which still results in a larger population spike

396 (t-Test, $p<0.01$ ), similar to what is observed in control (Figure 5.A3 vs 5.C3). This

397 result demonstrates that $\mathrm{GABA}_{B}$-mediated inhibitory transmission plays an important

398 role in the decrease in D-S coupling following HFS, but that this role is restricted to the

399 induction of this decrease, not in its maintenance and/or expression.

400

401

402 


\section{Discussion}

404 In this paper, we examined mechanisms underlying EPSP-Spike potentiation, the 405 persistent increase in EPSP-action potential coupling that occurs alongside the more 406 familiar Long-Term Potentiation (LTP). There are three obvious potential mechanisms 407 that might support E-S potentiation: 1) A lowering of the action potential threshold at the 408 postsynaptic spike trigger zone, 2) A greater survival of synaptic current as it moves

409 from its dendritic origin to the spike trigger zone, or 3) A decrease in inhibitory synaptic

410 shunts that usually serve to prevent current flow to the spike trigger zone. Here, we

411 examine the hypothesis that E-S potentiation is a result of both a suppression of

412 GABAergic transmission, and of potentially cell-autonomous changes in electrotonic

413 coupling between dendrite and soma allowing for more efficient current flow from 414 synapse to spike trigger zone.

416 Consistent with earlier findings, we found that application of the GABAA open

417 channel blocker Picrotoxin caused a maximal leftward shift in the E-S coupling curve,

418 and there was no further leftward shift when HFS was subsequently applied [9]. This

419 occurs because the area of the population spike, the measure of how many pyramidal

420 neurons have been brought to threshold, is saturated by the application of PTX.

421 However, we also found that this saturated leftward shift became persistent, not

422 reversed, upon washout of PTX from the slice, only if HFS was applied. Together these

423 findings show that PTX occludes the expression of E-S potentiation by maximizing the

424 population spike, but does not actually induce E-S potentiation or prevent it's induction

425 by high-frequency synaptic activity. 
While it is clear that GABAA transmission participates in E-S potentiation in some

427 way, and most likely represents one of the major mechanisms responsible for E-S

428 potentiation, it is not clear that a persistent reduction of $\mathrm{GABA}_{\mathrm{A}}$ transmission can

429 account for all of its expression. Previous studies have suggested either a decrease in

430 GABAergic signaling [6, 12, 14, 26, 27], no change in GABAergic signaling [27, 28],

431 partial participation of GABAergic signaling (40\%) [6], or even an increase in GABAergic

432 signaling $[4,27,29]$, many of these results in response to HFS. Nonetheless, in our

433 own recordings we have multiple lines of evidence that suggest a suppression of

434 inhibition specifically as a result of HFS as a major contributor to the expression of E-S

435 potentiation, including the presence of multiple population spikes that are produced only

436 after the induction of E-S potentiation, and are persistent for the duration of our

437 experiments (see population spike traces, Figures 1-5). Multiple studies that have

438 suppressed inhibition through a variety of pharmacological means, including our own

439 results using PTX (Figures 1.B2, 2.B2 3.C2), demonstrate the emergence of after-

440 discharge spiking as a direct result of suppressed inhibition [30-34].

The other major mechanism that might account for E-S potentiation is a change

443 in efficiency of charge transfer from dendrite to soma. We measured this D-S coupling

444 by comparing the dendritic EPSP field with the somatic EPSP field. Surprisingly, we

445 found that tetanic stimulation was followed by a persistent decrease in D-S coupling,

446 and that this decrease was prevented by application of the $\mathrm{GABA}_{\mathrm{B}}$ receptor antagonist

447 CGP-54626 when present during HFS. Thus, our original hypothesis that there would

448 be an increase in D-S coupling was incorrect. We revised this hypothesis to suggest 
449 that this decrease in coupling was mediated by a persistent potentiation of GABAB

450 transmission to the dendrite, but we discarded this hypothesis when we showed that

451 CGP application after HFS had no effect on the D-S coupling shift (CGP did not reverse

452 the shift once it occurred). Thus, we now hypothesize that the decrease in dendritic

453 coupling following tetanic stimulation is induced by $\mathrm{GABA}_{B}$ transmission, but is not

454 maintained by it.

455

It is unclear presently how GABAв transmission during the induction of LTP and

457 E-S potentiation may be driving the observed change in D-S coupling, but the most

458 likely explanation may involve changes in resting $\mathrm{K}^{+}$conductance that may lead to

459 greater shunting of electrotonic current from the synaptic origin to the soma. It is well

460 known that GABAв transmission is linked to $\mathrm{K}^{+}$conductance, and shows both increases

461 and decreases in conductance. $\mathrm{GABA}_{\mathrm{B}}$ has been shown to be strongly linked to Kir3

462 activity [24, 35], which may be playing a role here. The other candidate that may

463 explain our findings is a change in the cationic HCN channels that contribute to the $I_{h}$

464 current. This channel has been suggested to change expression bidirectionally along

465 the dendrites in response to various LTP induction methods [7, 8], and may shunt

466 excitability in response to LTP induction.

In summary, we have shown that High Frequency Stimulation results in synaptic

469 LTP, EPSP-Spike potentiation, and a reduction in Dendro-Somatic coupling. E-S

470 potentiation is not visible in the presence of the GABAA channel blocker Picrotoxin, but

471 only because of pre-saturation of excitability prior to tetanic stimulation. The underlying 
472 mechanism for the induction of E-S potentiation however, can still be induced in this

473 state, as its persistence is induced by HFS, even when additional potentiation of the

474 population spike is occluded. That the separate $\mathrm{GABA}_{\mathrm{B}}$-induced reduction in D-S

475 coupling still occurs even in the presence of PTX, suggests that a suppression of

476 GABAA inhibition in the soma, but not the dendrites, may contribute to the expression of

477 E-S potentiation. A reduction in D-S coupling does not occur in the presence of the

478 GABAв receptor antagonist CGP-54626, but E-S potentiation does occur. This also

479 suggests the locus of E-S potentiation is somatic, and that this mechanism is more

480 powerful than the GABA

Figure 6 shows a proposed model to summarize and explain the results

483 presented in this paper. Each panel shows a schematic representation of current flow

484 with the width of each blue arrow indicating the decay in the amount of current as it

485 travels from the dendritic excitatory synapses towards the spike trigger zone. Pre-HFS

486 control conditions are on the left of each panel, and post HFS potentiated conditions are

487 on the right, separated by the dashed line. In this model, current is shunted out through

488 passive dendritic conductance (blue split-out arrows) and via synaptic inhibition (red

489 arrows). $\mathrm{GABA}_{\mathrm{B}}$ transmission may provide some neutralization/shunting in the dendrite

490 of the excitatory synaptic current, but this does not change after potentiation. However,

491 activation of the $\mathrm{GABA}_{\mathrm{B}}$ receptor during HFS does appear to induce a process that

492 persistently changes the passive dendritic shunt (gold arrows). The current that

493 survives to the soma is subject to being neutralized by $\mathrm{GABA}_{A}$-mediated transmission,

494 which is decreased persistently after HFS, leading to greater excitatory current reaching 
495 the spike trigger zone. Panel A illustrates the proposed changes after HFS with

496 potentiation of the synaptic input, while panel B shows the same process, but when the

497 synaptic input is potentiated, but then matched to the pre-HFS level by turning down the

498 stimulus. The schematic width of the blue arrows is designed to show how HFS can

499 cause a decrease in dendritic coupling and still result in greater action potential

500 discharge at the spike trigger zone due to an over-balanced reduction in GABAA

501 transmission at the soma.

502

503

A combination of LTP and E-S potentiation induced together, as illustrated in

504 Figure 6, would serve to make the EPSP more effective in reaching action potential

505 threshold. Since the final common path of a cell's participation in neural information

506 transfer is whether or not it emits an action potential, it is likely that the importance of E-

507 S potentiation has been underestimated in the participation of plasticity of neural

508 circuits, and its role in cognitive processes such as learning and memory. As a

509 persistent increase in synaptic evocation of spike output, there is no reason to suppose

510 that it could not participate in memory trace formation, and if it can be induced

511 independently of LTP as has been suggested (2), then it could serve as an alternate

512 path to such engram formation. Furthermore, if the decrease in dendritic coupling that

513 accompanies E-S potentiation, previously unreported, could also be induced

514 independently, something that has not yet been demonstrated, this could be a

515 mechanism to weaken the expression of such engrammatic traces. In any case, it

516 appears to be a mechanism by which a additional layer of the control of synapse-to-

517 spike coupling can be modulated. These findings advance our understanding of 
518 information processing at a level of both the individual neuron, and the hippocampal

519 microcircuit, and provide a better understanding and a greater appreciation of the role in

520 E-S potentiation and the mechanisms that regulate its play in the information processing

521 inside the neural circuitry. 


\section{$\underline{\text { References }}$}

1. Bliss, T.V. and T. Lomo, Long-lasting potentiation of synaptic transmission in the dentate area of the anaesthetized rabbit following stimulation of the perforant path. J Physiol, 1973. 232(2): p. 331-56.

2. Jester, J.M., L.W. Campbell, and T.J. Sejnowski, Associative EPSP--spike potentiation induced by pairing orthodromic and antidromic stimulation in rat hippocampal slices. J Physiol, 1995. 484 ( Pt 3): p. 689-705.

3. Fink, A.E. and T.J. O'Dell, Short trains of theta frequency stimulation enhance CA1 pyramidal neuron excitability in the absence of synaptic potentiation. $\mathrm{J}$ Neurosci, 2009. 29(36): p. 11203-14.

4. Taube, J.S. and P.A. Schwartzkroin, Mechanisms of long-term potentiation: EPSP/spike dissociation, intradendritic recordings, and glutamate sensitivity. J Neurosci, 1988. 8(5): p. 1632-44.

5. Chavez-Noriega, L.E., T.V. Bliss, and J.V. Halliwell, The EPSP-spike (E-S) component of long-term potentiation in the rat hippocampal slice is modulated by GABAergic but not cholinergic mechanisms. Neurosci Lett, 1989. 104(1-2): p. 5864.

6. Daoudal, G., Y. Hanada, and D. Debanne, Bidirectional plasticity of excitatory postsynaptic potential (EPSP)-spike coupling in CA1 hippocampal pyramidal neurons. Proc Natl Acad Sci U S A, 2002. 99(22): p. 14512-7. 
7. Campanac, E., et al., Downregulation of dendritic I(h) in CA1 pyramidal neurons after LTP. J Neurosci, 2008. 28(34): p. 8635-43.

8. Fan, Y., et al., Activity-dependent decrease of excitability in rat hippocampal neurons through increases in I(h). Nat Neurosci, 2005. 8(11): p. 1542-51.

9. Abraham, W.C., B. Gustafsson, and H. Wigstrom, Long-term potentiation involves enhanced synaptic excitation relative to synaptic inhibition in guinea-pig hippocampus. J Physiol, 1987. 394: p. 367-80.

10. Marder, C.P. and D.V. Buonomano, Differential effects of short- and long-term potentiation on cell firing in the CA1 region of the hippocampus. J Neurosci, 2003. 23(1): p. 112-21.

11. Staff, N.P. and N. Spruston, Intracellular correlate of EPSP-spike potentiation in CA1 pyramidal neurons is controlled by GABAergic modulation. Hippocampus, 2003. 13(7): p. 801-5.

12. Lu, Y.M., et al., Calcineurin-mediated LTD of GABAergic inhibition underlies the increased excitability of CA1 neurons associated with LTP. Neuron, 2000. 26(1): p. 197-205.

13. Orr, A.L., et al., beta-Amyloid inhibits E-S potentiation through suppression of cannabinoid receptor 1-dependent synaptic disinhibition. Neuron, 2014. 82(6): p. $1334-45$. 
14. Laezza, F., J.J. Doherty, and R. Dingledine, Long-term depression in hippocampal interneurons: joint requirement for pre- and postsynaptic events. Science, 1999. 285(5432): p. 1411-4.

15. Kairiss, E.W., et al., Field potential evidence for long-term potentiation of feedforward inhibition in the rat dentate gyrus. Brain Res, 1987. 401(1): p. 87-94.

16. Alger, B.E. and R.A. Nicoll, Pharmacological evidence for two kinds of GABA receptor on rat hippocampal pyramidal cells studied in vitro. J Physiol, 1982. 328: p. 125-41.

17. Sourdet, V., et al., Long-term enhancement of neuronal excitability and temporal fidelity mediated by metabotropic glutamate receptor subtype 5. J Neurosci, 2003. 23(32): p. 10238-48.

18. Frick, A., J. Magee, and D. Johnston, LTP is accompanied by an enhanced local excitability of pyramidal neuron dendrites. Nat Neurosci, 2004. 7(2): p. 126-35.

19. Wang, W., N. Gong, and T.L. Xu, Downregulation of KCC2 following LTP contributes to EPSP-spike potentiation in rat hippocampus. Biochem Biophys Res Commun, 2006. 343(4): p. 1209-15.

20. Chevaleyre, V. and P.E. Castillo, Heterosynaptic LTD of hippocampal GABAergic synapses: a novel role of endocannabinoids in regulating excitability. Neuron, 2003. 38(3): p. 461-72. 
21. Chavez-Noriega, L.E., J.V. Halliwell, and T.V. Bliss, $A$ decrease in firing threshold observed after induction of the EPSP-spike (E-S) component of longterm potentiation in rat hippocampal slices. Exp Brain Res, 1990. 79(3): p. 63341.

22. Tomasulo, R.A., W.B. Levy, and O. Steward, LTP-associated EPSP/spike dissociation in the dentate gyrus: GABAergic and non-GABAergic components. Brain Res, 1991. 561(1): p. 27-34.

23. Abraham, W.C. and T.V. Bliss, An analysis of the increase in granule cell excitability accompanying habituation in the dentate gyrus of the anesthetized rat. Brain Res, 1985. 331(2): p. 303-13.

24. Degro, C.E., et al., Compartmental distribution of GABAB receptor-mediated currents along the somatodendritic axis of hippocampal principal cells. Front Synaptic Neurosci, 2015. 7: p. 6.

25. Pettit, D.L. and G.J. Augustine, Distribution of functional glutamate and GABA receptors on hippocampal pyramidal cells and interneurons. J Neurophysiol, 2000. 84(1): p. 28-38.

26. Stelzer, A., N.T. Slater, and G. ten Bruggencate, Activation of NMDA receptors blocks GABAergic inhibition in an in vitro model of epilepsy. Nature, 1987. 326(6114): p. 698-701. 
27. Stelzer, A., et al., Synaptic disinhibition during maintenance of long-term potentiation in the CA1 hippocampal subfield. Proc Natl Acad Sci U S A, 1994. 91(8): p. 3058-62.

28. Marder, C.P. and D.V. Buonomano, Timing and balance of inhibition enhance the effect of long-term potentiation on cell firing. J Neurosci, 2004 . 24(40): p. 887384.

29. Grunze, H.C., et al., NMDA-dependent modulation of CA1 local circuit inhibition. J Neurosci, 1996. 16(6): p. 2034-43.

30. Madison, D.V. and R.A. Nicoll, Norepinephrine decreases synaptic inhibition in the rat hippocampus. Brain Res, 1988. 442(1): p. 131-8.

31. Miles, R., R.K. Wong, and R.D. Traub, Synchronized afterdischarges in the hippocampus: contribution of local synaptic interactions. Neuroscience, 1984. 12(4): p. 1179-89.

32. Ault, B. and J.V. Nadler, Anticonvulsant-like actions of baclofen in the rat hippocampal slice. Br J Pharmacol, 1983. 78(4): p. 701-8.

33. Schwartzkroin, P.A. and D.A. Prince, Changes in excitatory and inhibitory synaptic potentials leading to epileptogenic activity. Brain Res, 1980. 183(1): p. $61-76$.

34. Wong, R.K. and D.A. Prince, Dendritic mechanisms underlying penicillin-induced epileptiform activity. Science, 1979. 204(4398): p. 1228-31. 
35. Fowler, C.E., et al., Evidence for association of $G A B A(B)$ receptors with Kir3 channels and regulators of G protein signalling (RGS4) proteins. J Physiol, 2007. 580(Pt 1): p. 51-65. 


\section{Figure 1}

A

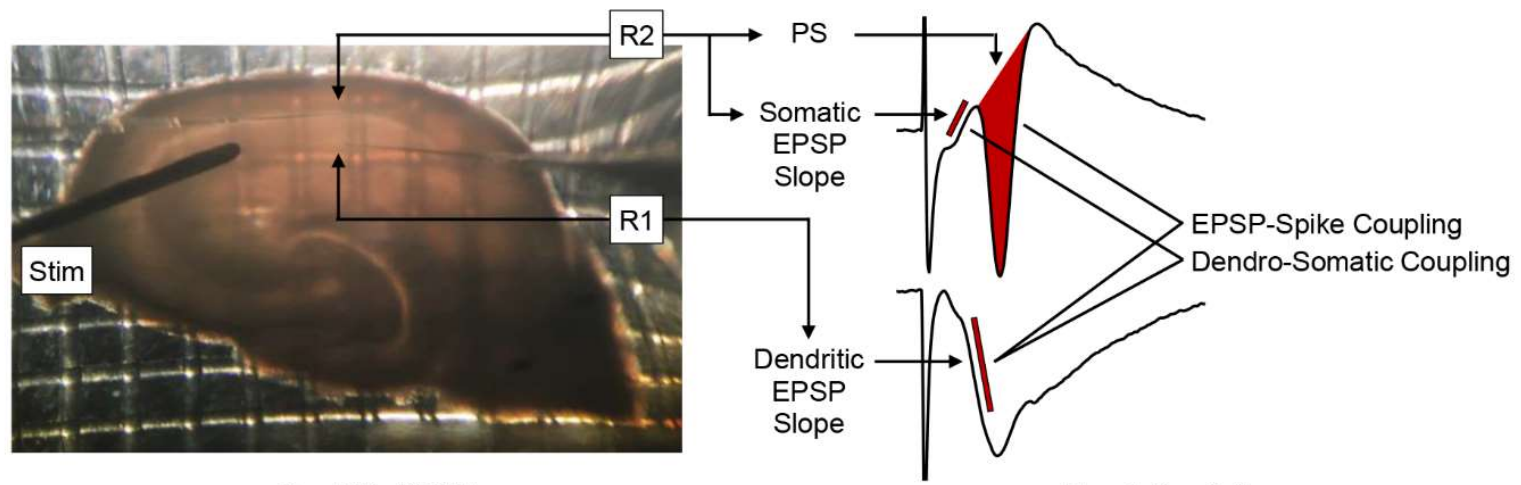

B1

Dendritic EPSP

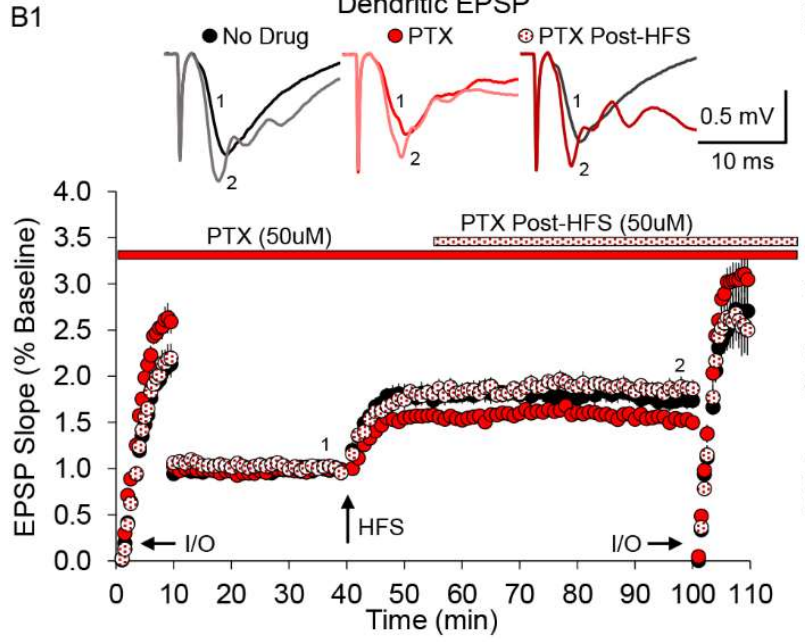

B2

Population Spike

C1

No Drug
- EPSP Before HFS $\triangle$ PS Before HFS C2

PTX
HFS $\triangle$ PS Before HFS
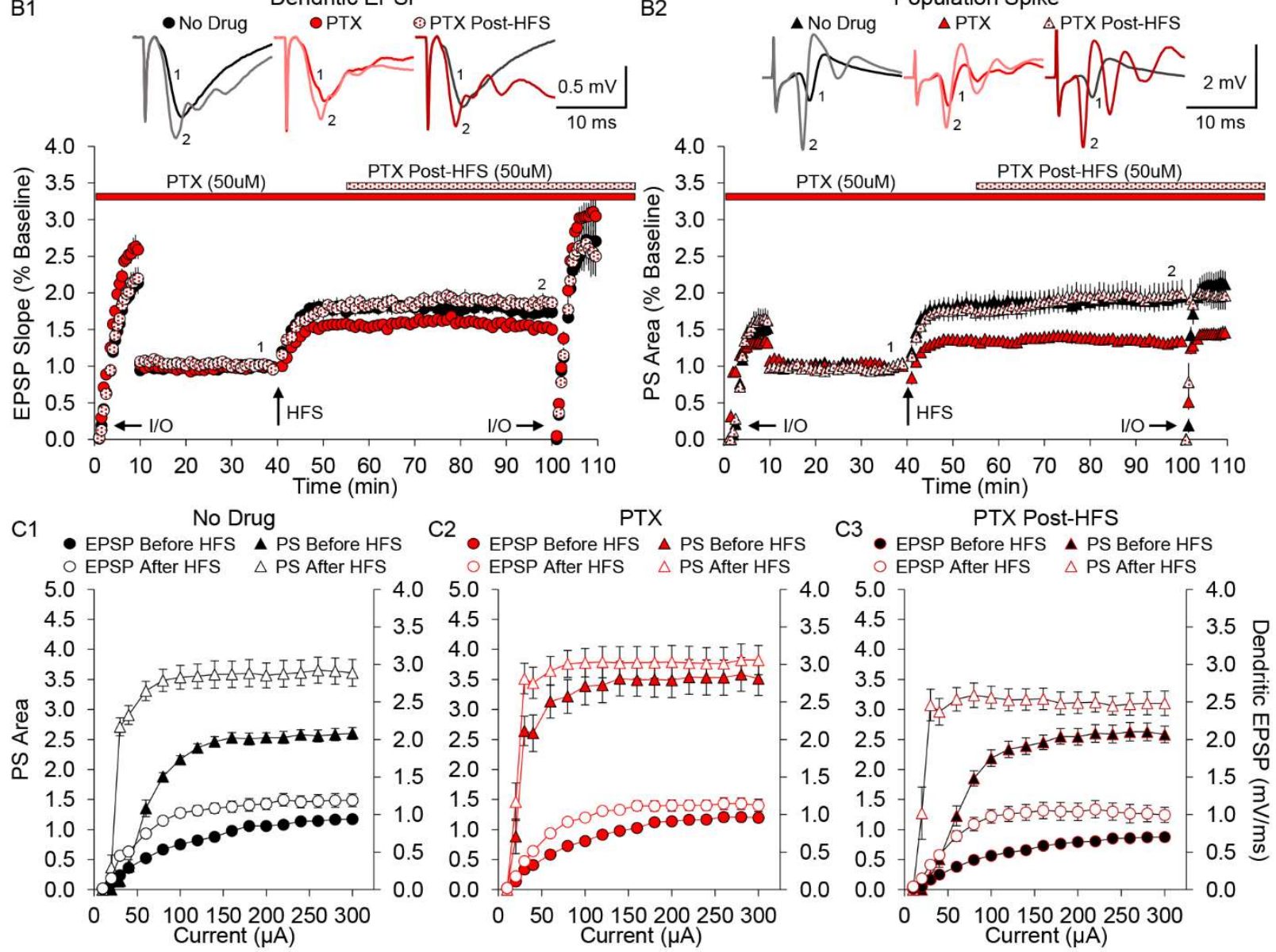
Figure 1: Picrotoxin reduces potentiation of the population spike when applied before, but not after HFS. A. A Hippocampal slice showing the placement of the stimulating electrode (Stim) in stratum radiatum near the CA2/CA1 border, and two recording electrodes (R1 and $\mathrm{R} 2$ ) in area CA1: one in stratum (s.) radiatum where Schaffer collateral synapses terminate on CA1 pyramidal cell dendrites (R1), and the other in s. pyramidal where the CA1 pyramidal cell bodies are located (R2). To the right are exemplar field potentials from these two electrodes showing the zone of measurement of the rising slope of the dendritic EPSP field (lower trace), the zone of measurement of the rising slope of the somatic EPSP field and the measurement of the area of the first population spike (upper trace). B1. The time-course of experiments showing the effects of HFS (up arrow) on the dendritic EPSP field in the presence of the GABAA channel blocker Picrotoxin (PTX) $(50 \mu \mathrm{M})$ applied either before or after HFS. Filled black symbols: No Drug control; red filled symbols: PTX present throughout experiment; red hatched symbols: PTX applied post-HFS. Time of delivery of PTX for each condition is indicated by the red bar (PTX present throughout experiment) or by the hatched bar (PTX applied 15 min post-HFS) located above the plot. An Input/Output curve was constructed at the beginning and end of each experiment (indicated by $\mathrm{I} / \mathrm{O}$ arrows at the bottom of the plot). Application of PTX post-HFS resulted in a field EPSP that was higher than when PTX was applied throughout the experiment, though neither PTX nor PTX post-HFS groups were different than No Drug control (No Drug: $73 \pm 8 \%, n=12$; PTX: $52 \pm 3 \%, n=12$; PTX post-HFS: $86 \pm 9 \%, n=10)$ as determined by ANOVA $(F(2,31)=5.65, p<0.01)$. B2. The population spike recorded simultaneously with the EPSPs in B1. PTX applied before HFS reduced the potentiation of the population spike 
by HFS, but had no effect when applied after HFS, which was similar to No Drug control (No Drug: $93 \pm$ 15\%; PTX: $33 \pm 5 \%$; PTX post-HFS: $97 \pm 19 \%)(F(2,31)=7.38, p<0.01)$. Averaged traces before (1) and after (2) HFS are displayed above the plots for each of the three conditions, and the corresponding time points for these averaged traces are indicated on the LTP time-course below. C. Input/Output curves constructed from a series of standardized stimulus strengths at the beginning and end of each experiment (visible in the LTP plots of panel B indicated by the I/O arrows). The two upper series in each graph are the population spike area (left axis on each graph), and the two lower series are the field EPSP slope (right axis on each graph). Each graph shows I/O curves before (filled symbols) and after (open symbols) HFS. Note: Recordings for each $\mathrm{I} / \mathrm{O}$ curve in panel $\mathrm{C}$ are the same as in panel $\mathrm{B}$. The $\mathrm{I} / \mathrm{O}$ curves represented in the LTP time-course plots (panel B) are normalized values relative to baseline measurements before HFS, while values in panel $\mathrm{C}$ are the absolute values for population spike area and EPSP slope. Stimulus strengths are 10, 20, 30, 40, 60, 80, $100,120,140,160,180,200,220,240,260,280$, and $300 \mu A$. Data shown represent the mean \pm SEM. 


\section{Figure 2:}
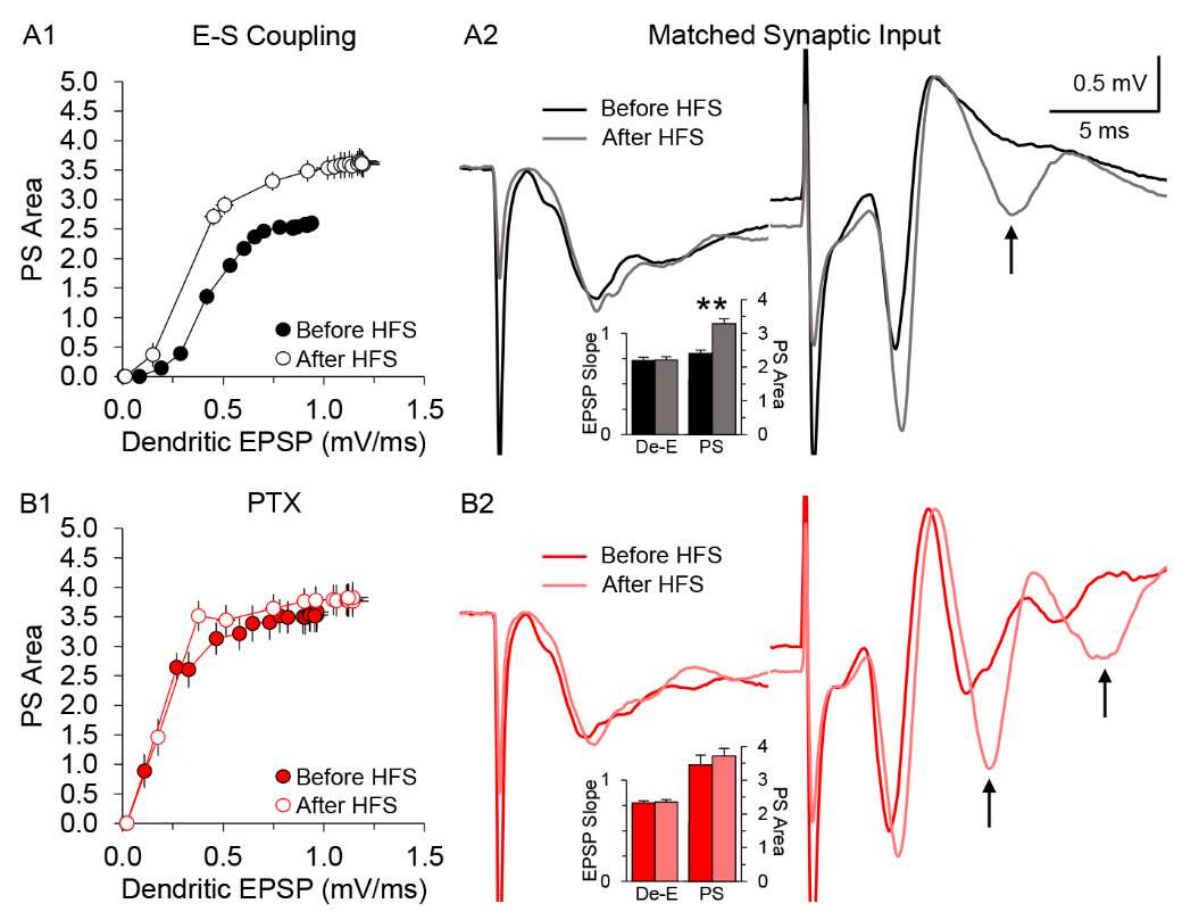

B2

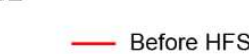

— Before HFS
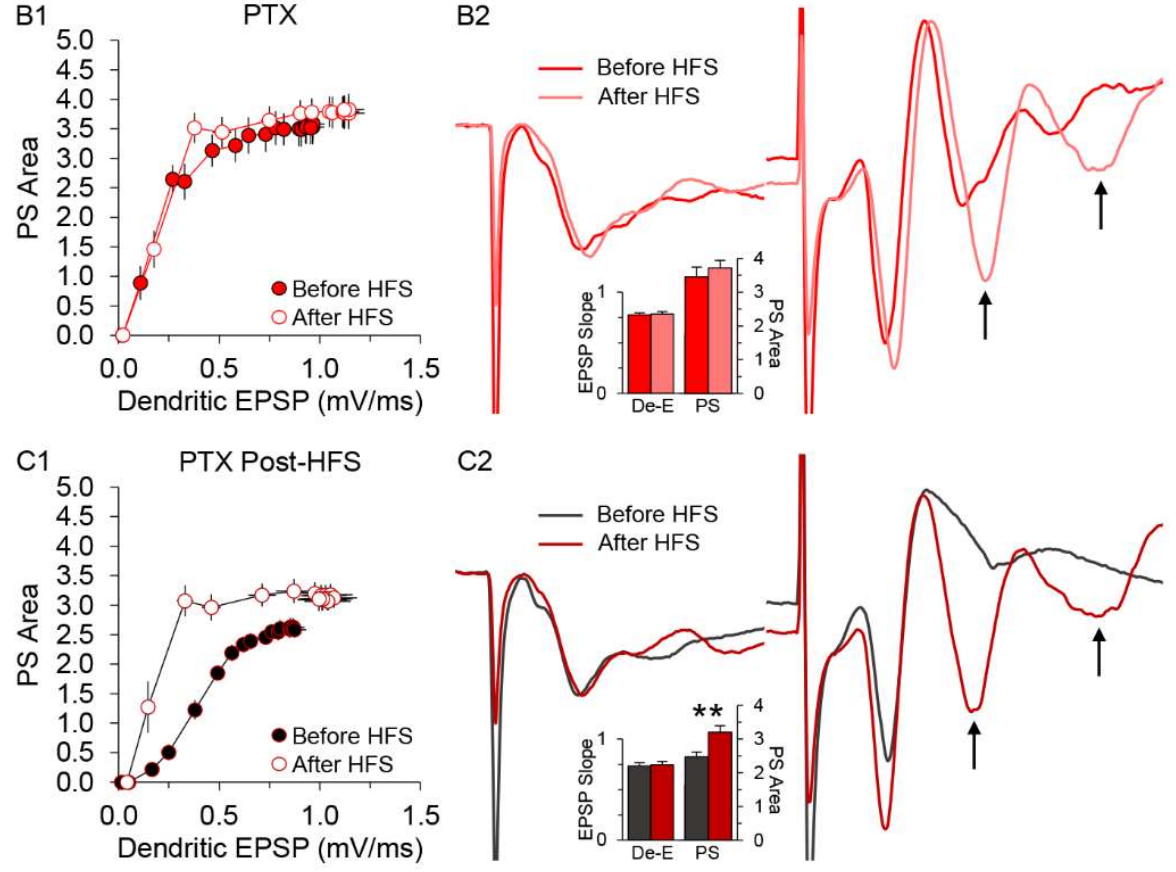

$\mathrm{C} 2$
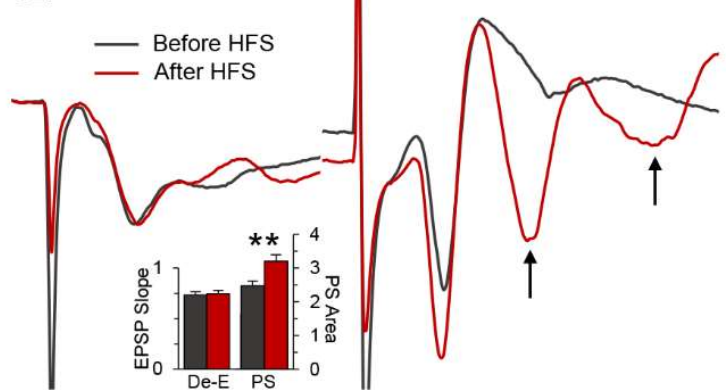
Figure 2: Shift in E-S coupling by HFS and Picrotoxin. The left column panels are E-S coupling curves constructed by plotting the population spike area against dendritic EPSP slope (see Figure 1A for reference), data taken from the $1 / O$ curves of figure $1 \mathrm{C}$. A1. E-S coupling curves before and after HFS under No Drug control conditions (no PTX present). HFS causes a persistent leftward shift in the curve. A2. Averaged traces of input matched dendritic EPSPs (left traces) and the resulting simultaneouslyrecorded population spikes (right traces) before and after HFS. Traces after HFS have a reduced stimulus strength to match the rising slope of the dendritic EPSP to that of the dendritic EPSP before HFS. Dendritic EPSPs after HFS generate a larger population spike compared to matched dendritic EPSPs before HFS. This results in the persistent leftward shift in the E-S coupling curve throughout the range of synaptic input as shown in A1. The observed change in E-S coupling is indicative of EPSP-Spike potentiation, and is demonstrated by the larger population spike shown in A2. The inset bar graph in A2 shows the significant potentiation of the population spike (PS) with matched dendritic EPSPs (De-E) before (black bar) and after (dark grey bar) HFS (tTest, $p<0.01$ ). B1. E-S coupling curves with PTX present at the time of HFS and throughout the experiment. There is no leftward shift in the E-S coupling curve after HFS. B2. The population spike is not different with input matched dendritic EPSPs before and after HFS in the presence of PTX. There is no leftward shift in the E-S coupling curve throughout the range of synaptic input as shown in B1, indicating EPSPSpike potentiation does not occur when PTX is present during HFS, also shown by the inset bar graph comparing responses before (red bar) and after (light red bar) HFS (tTest, $p=0.48)$. C1. E-S coupling curves without PTX during HFS, but added post-HFS. 
HFS causes a persistent leftward shift in the curve, similar to that seen in control. C2. Input matched dendritic EPSPs produce a greater population spike after HFS compared to before. This is observed by the persistent leftward shift in the E-S coupling curve throughout the range of synaptic input, indicating EPSP-Spike potentiation occurs when PTX is not present during HFS, also shown by the inset bar graph comparing responses before (dark grey bar) and after (dark red bar) HFS (t-Test, $p<0.01)$. Note the afterdischarge spike(s), indicated by the arrows, in the population spike trace after HFS in all groups, thought to occur as a result of reduced inhibition following HFS (No Drug), or a combination of HFS and drug application (PTX, PTX post-HFS). Data shown represent the mean \pm SEM. Bar graph data are generated from matched dendritic EPSP slopes and resulting population spike areas taken from Input/Output curves before and after HFS from panel 1C. Recorded traces for each matched pair were averaged and shown here in A2, B2, and C2 respectively for each group. 


\section{Figure 3:}
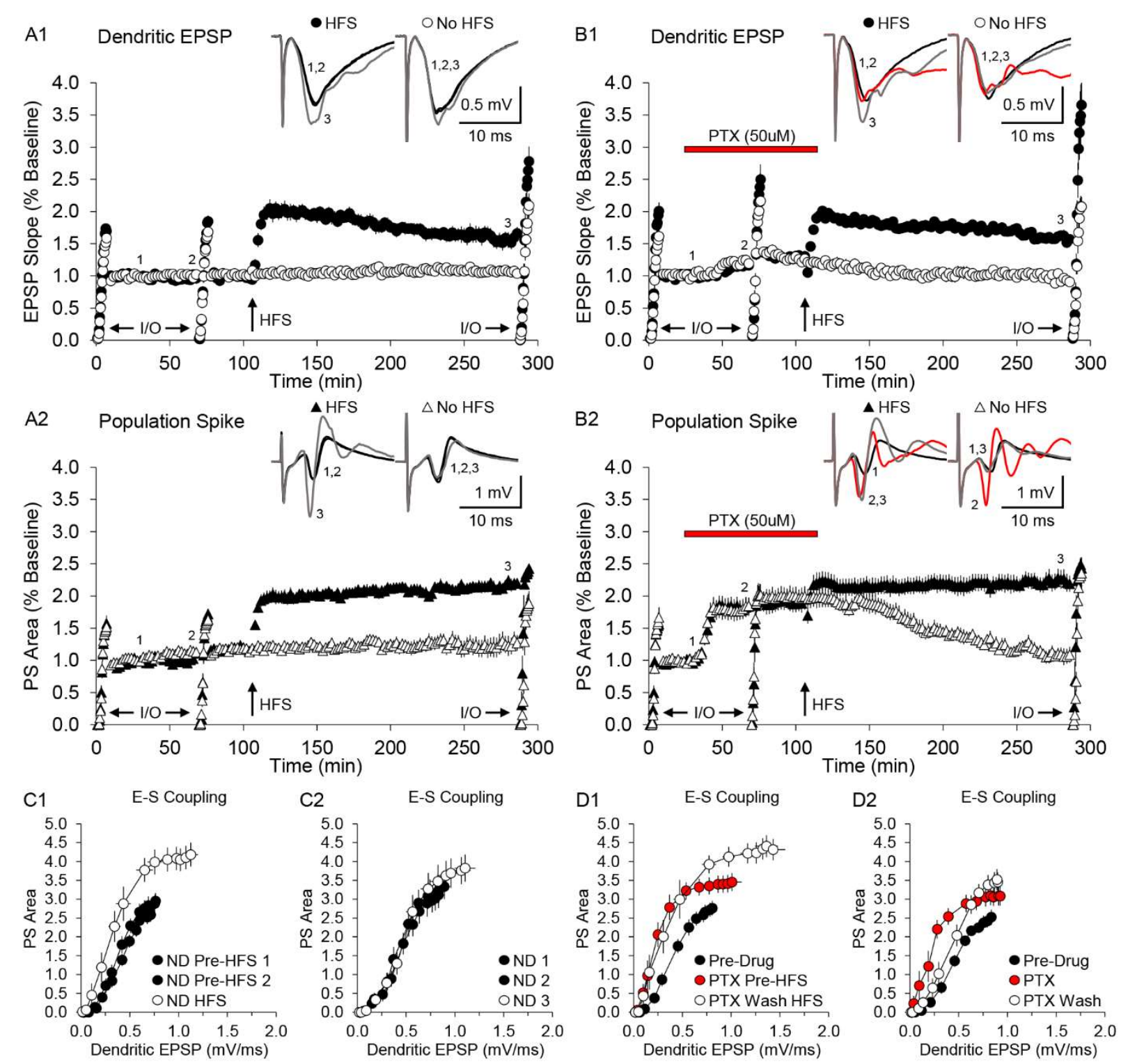
Figure 3: EPSP-Spike Potentiation is occluded, not blocked, by Picrotoxin. A and B. The effects of PTX application on basal activity of dendritic EPSPs and resulting population spikes, and subsequent washout either with or without HFS. Each experiment shows an HFS (filled symbols) vs. No HFS (open symbols) comparison. Three different Input/Output curves were constructed (indicated by the I/O arrows): at the beginning of the experiment, after the application of PTX (50 $\mu \mathrm{M}$, red bar located above the plot) but before HFS, and at the end of each experiment. A. No Drug control condition for the dendritic EPSP (A1) and population spike (A2). B. Same experiment as in panel A, except with the application of HFS during application of PTX, then subsequently washed out (PTX-WO) starting five minutes post-HFS. Data shown in all experiments are normalized to the 5 minutes immediately prior to PTX application. The presence of PTX had no effect on the induction of LTP of the dendritic EPSP field (A1 vs B1), and following PTX washout, was not different from control (HFS - No Drug: $59 \pm$ 10\%, n=9; PTX-WO: $56 \pm 7 \%, n=10)$. Experiments in which no HFS was performed showed responses after PTX washout were not different from control, indicating no lasting effects of PTX application only (no HFS - No Drug: $6 \pm 6 \%, n=8$; PTX-WO: $-6 \pm$ $6 \%, n=9)$. However, PTX caused a significant increase in the population spike (B2) compared to the same time point in the control (A2) (No Drug: $8 \pm 6 \%$; PTX: $81 \pm 14 \%$; t-Test, $p<0.01)$. HFS caused no further significant increase in the population spike, and upon PTX washout, remained potentiated, and was not different than the population spike after HFS in control (HFS - No Drug: $121 \pm 7 \%$; PTX-WO: $122 \pm 13 \%$ ). Without HFS, washout of PTX returned the population of spike to baseline and was not different from control conditions without HFS (no HFS - No Drug: $25 \pm 13 \%$; PTX-WO: $6 \pm 12 \%$ ). 
Averaged traces at three different time points are displayed above the plots for each condition, and the corresponding time points for these averaged traces are indicated on the LTP time-course below. The red trace in panel B indicates the presence of PTX. C and D. E-S coupling curves constructed from the experiments in panels A and B above. C1. No Drug control with HFS: $1^{\text {st }}$ and $2^{\text {nd }}$ E-S curves before HFS are similar, but following HFS there is a persistent leftward shift in the E-S coupling curve. C2. No Drug control without HFS: There is no change in E-S coupling throughout the duration of the experiment. D1. PTX with HFS: Application of PTX caused a leftward shift in the E-S coupling curve (red vs. black symbols) that persisted upon PTX washout if HFS was performed in the presence of PTX (open symbols). D2. PTX without HFS: Application of PTX caused a leftward shift in the E-S coupling curve that was reversed upon PTX washout if no HFS was performed. Data shown represent the mean \pm SEM. 


\section{Figure 4:}
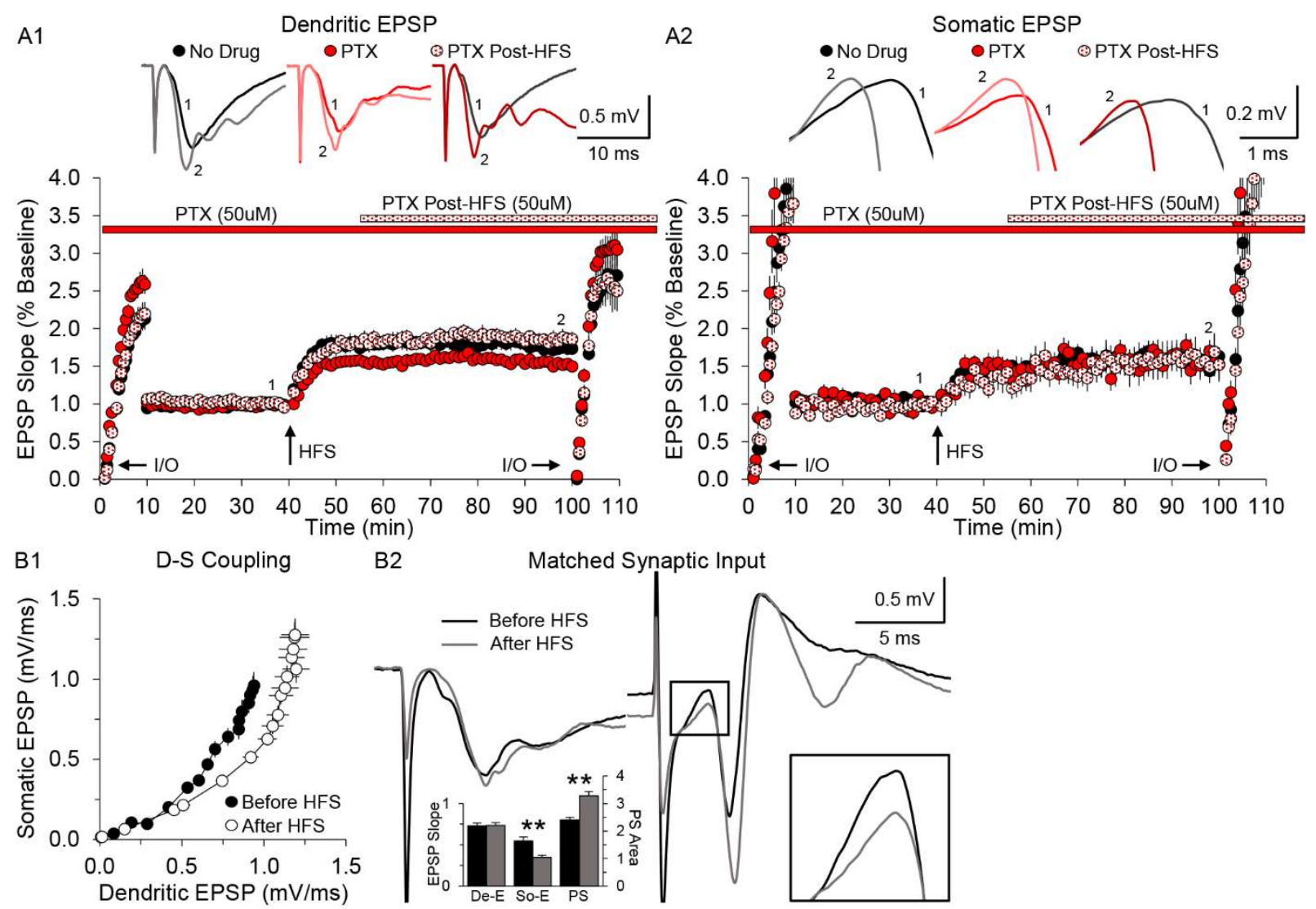

naptic Input
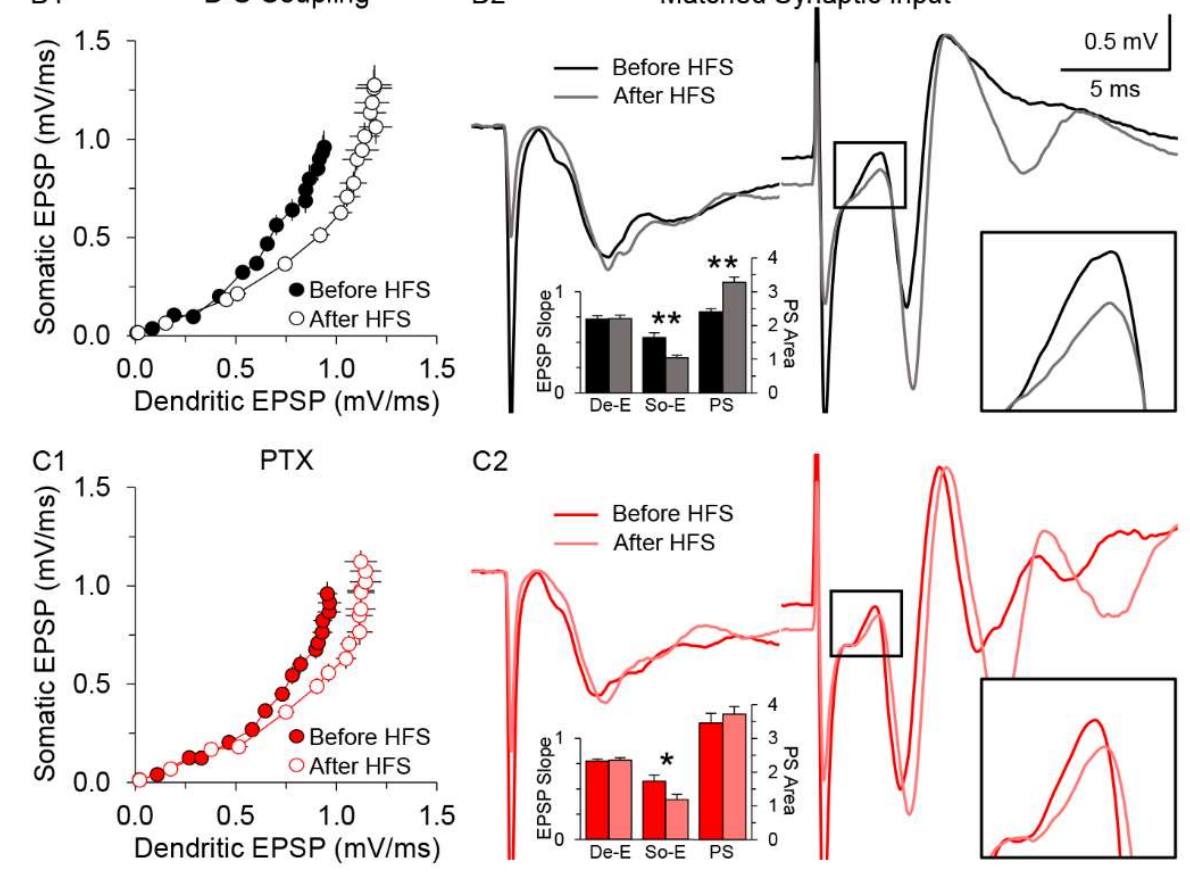

C2
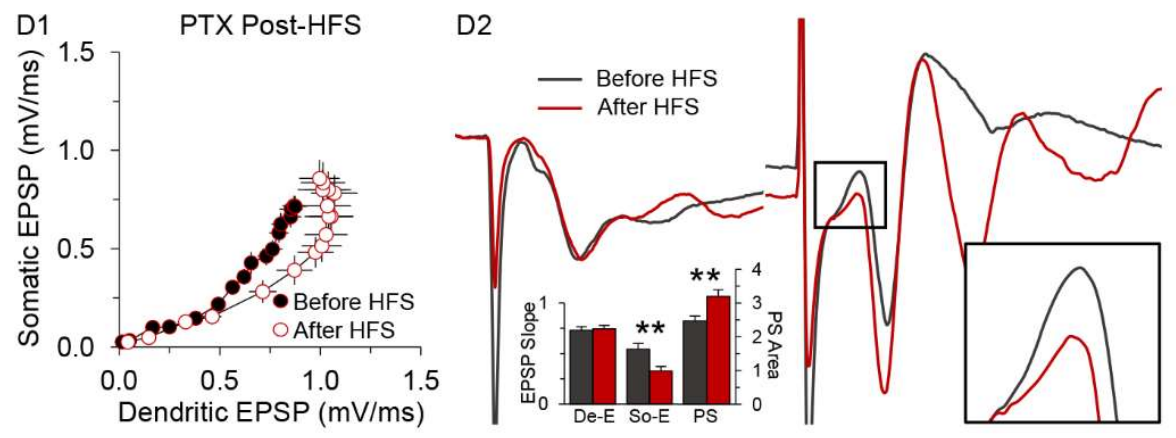
Figure 4: Dendro-Somatic (D-S) coupling is decreased after HFS. A. The time-course of experiments showing the effects of HFS (up arrow) on the dendritic EPSP field (A1) or somatic EPSP field (A2) in the presence of PTX (50 $\mu \mathrm{M})$ applied either before or after HFS. Filled black symbols: No Drug control; red filled symbols: PTX present throughout experiment; red hatched symbols: PTX applied post-HFS. Time of delivery of PTX for each condition is indicated by the red bar (PTX present throughout experiment) or by the hatched bar (PTX applied 15 min post-HFS) located above the plot. An Input/Output curve was constructed at the beginning and end of each experiment (indicated by $\mathrm{I} / \mathrm{O}$ arrows at the bottom of the plot) and used to construct the D-S coupling curves shown in parts B-D below. A1. Time-course of experiments showing the effects of HFS and PTX application on the dendritic EPSP field. Experiments are the same as in Figure 1.B1, and are shown here for comparison. A2. Time-course of experiments showing the effects of HFS and PTX application on the somatic EPSP field. The somatic EPSP field is the reflective field of the dendritic EPSP field, and is measured at the soma. Somatic EPSP slope data is taken from the simultaneous population spike field recording (see Figure $1 \mathrm{~A}$ for reference). Long-Term potentiation of the somatic EPSP field was not different in any of the three conditions (No Drug: $56 \pm$ $8 \%, n=12$; PTX: $56 \pm 14 \%, n=12$; PTX post-HFS: $57 \pm 21 \%, n=10$ ). Averaged traces before (1) and after (2) HFS are displayed above the plots for each of the three conditions, and the corresponding time points for these averaged traces are indicated on the LTP time-course below. B1, C1, and D1. D-S coupling curves constructed by plotting the somatic EPSP slope against the dendritic EPSP slope (see Figure 1A for 
reference), data taken from the absolute values of $\mathrm{I} / \mathrm{O}$ curves generated in the experiments shown above (also shown in Figure 1B). In all conditions there is a persistent shift in the D-S coupling curve to the right, not the left as seen with the E-S coupling curves. This indicates the electrical coupling between the dendritic input and the soma is decreased after HFS, opposite of what is observed with E-S coupling. B2, C2, and D2. Averaged traces of input matched dendritic EPSPs (left traces) and the resulting simultaneously-recorded population spikes with the somatic EPSPs highlighted and magnified in the boxed region (right traces) before and after HFS. Traces after HFS have a reduced stimulus strength to match the rising slope of the dendritic EPSP to that of the dendritic EPSP before HFS. In all conditions, matched dendritic EPSPS after HFS give rise to smaller somatic EPSPs compared to matched dendritic EPSPs before HFS. This results in the persistent rightward shift in the D-S coupling curve throughout the range of synaptic input as shown in B1, C1, and D1. The inset bar graphs show the show the significant reduction in the somatic EPSP (So-E) with matched dendritic EPSPs (De-E) after HFS compared to before (t-Test; No Drug and PTX post-HFS, $p<0.01$; PTX, $p<0.05)$. The accompanying population spike data from Figure 2 is also shown here for comparison. Despite there being a reduction in the somatic EPSP for a matched dendritic input after HFS, there is still a larger population spike than before HFS with matched synaptic inputs in the No Drug control and PTX post-HFS groups. This is not seen when PTX is applied throughout. However, note that PTX does not influence the relationship between the dendritic and somatic EPSP fields as there is still a reduction in the somatic EPSP after HFS, suggesting that changes in $\mathrm{GABA}_{\mathrm{A}}$ transmission has no, or minimal, participation in changes to D-S 
coupling. Data shown represent the mean \pm SEM. Bar graph data are generated from matched dendritic EPSP slopes and resulting somatic EPSP slopes taken from Input/Output curves before and after HFS. Recorded traces for each matched pair were averaged and shown here in B2, C2, and D2 respectively for each group. 


\section{Figure 5:}
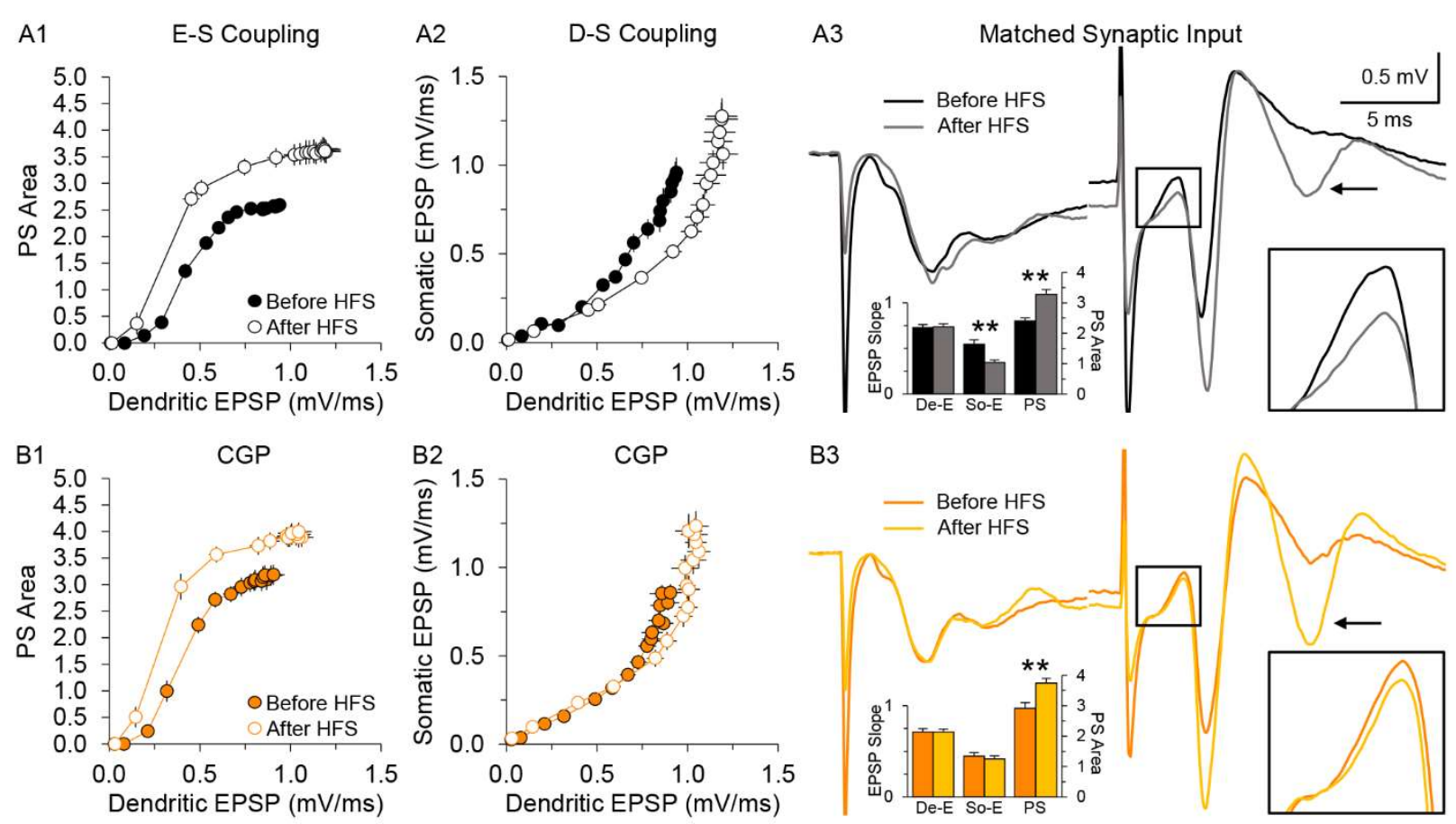

B3
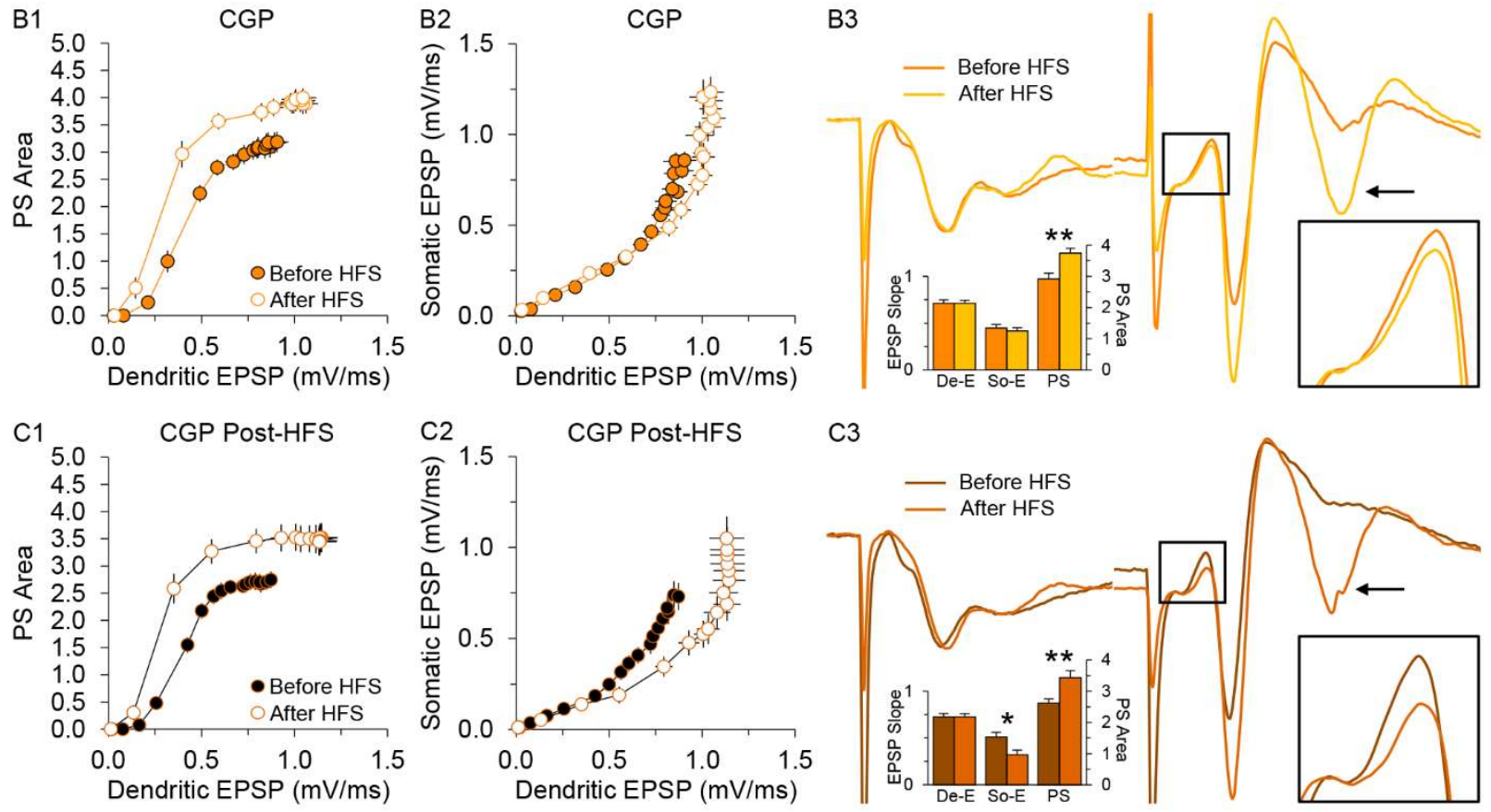
Figure 5: HFS-induced reduction in the induction, but not the maintenance or expression of Dendro-Somatic coupling, depends on the GABAв receptor. Experiments were conducted identically to those carried out with PTX, with the GABAB receptor antagonist CGP-54626 (CGP) $(3 \mu \mathrm{M})$ used in place of PTX. All E-S coupling curves in this figure were constructed in an identical manner as those in the earlier PTX experiments. A. The No Drug control data $(n=12)$ is the same as that shown in Figures 2 and 4, shown here for comparison. HFS resulted in a leftward shift in the E-S coupling curve (A1), and a rightward shift in the D-S coupling curve (A2). Matched dendritic EPSPs before and after HFS resulted in a smaller somatic EPSP (t-Test, $p<$ 0.01) and larger population spike (t-Test, $p<0.01$ ) after HFS compared to before HFS (A3), demonstrating EPSP-Spike potentiation and a change in D-S coupling. B1 and B2. When CGP was present during HFS, there was a persistent leftward shift in the E-S coupling curve (B1), but no change in the D-S coupling curve (B2), abolishing the rightward shift as was seen in the control. B3. Matched dendritic EPSPs give rise to somatic EPSPs that are not different, but generate larger population spikes, after HFS compared to before. This result agrees with the persistent leftward shift seen in the E-S coupling curve, but no shift in the D-S coupling curve, throughout the range of synaptic input (B1, B2). The inset bar graph shows no difference in the somatic EPSP (So-E) with matched dendritic EPSPs (De-E) after HFS (light orange bars) compared to before (orange bars)(t-Test, $p=0.55, n=10)$, which seems to have no effect on $E-S$ coupling since the population spike (PS) was significantly potentiated (t-Test, $p<0.01)$ after HFS, indicative of E-S potentiation. C1 and C2. When CGP was applied after HFS, it had no effect on either E-S coupling (C1) or D-S coupling (C2), producing results similar 
to control. C3. Matched dendritic EPSPs before (brown bars) and after (dark orange bars) HFS gave rise to a smaller somatic EPSP (t-Test, $\mathrm{p}<0.05, \mathrm{n}=10$ ) and larger population spike (t-Test, $\mathrm{p}<0.01)$ after HFS, demonstrating EPSP-Spike potentiation and a change in D-S coupling similar to that seen in control. This suggests that GABAB activity is required for the induction of the decrease in D-S coupling, but does not participate in its maintenance or expression. Note the afterdischarge spike(s), indicated by the arrows, in the population spike trace after HFS in all groups, thought to occur as a result of reduced inhibition following HFS (No Drug), or a combination of HFS and drug application (CGP, CGP post-HFS). Unlike the multiple afterdischarge spiking seen in PTX experiments, CGP seems to only enhance (visual observation, not quantified) a single afterdischarge spike. Data shown represent the mean \pm SEM. Bar graph data are generated from matched dendritic EPSP slopes and resulting somatic EPSP slopes and population spike areas taken from Input/Output curves before and after HFS (Data not shown). Recorded traces for each matched pair were averaged and shown here in A3, B3, and C3 respectively for each group. 
bioRxiv preprint doi: https://doi.org/10.1101/2020.02.21.960138; this version posted February 25, 2020. The copyright holder for this preprint (which was not certified by peer review) is the author/funder. All rights reserved. No reuse allowed without permission.

Figure 6:

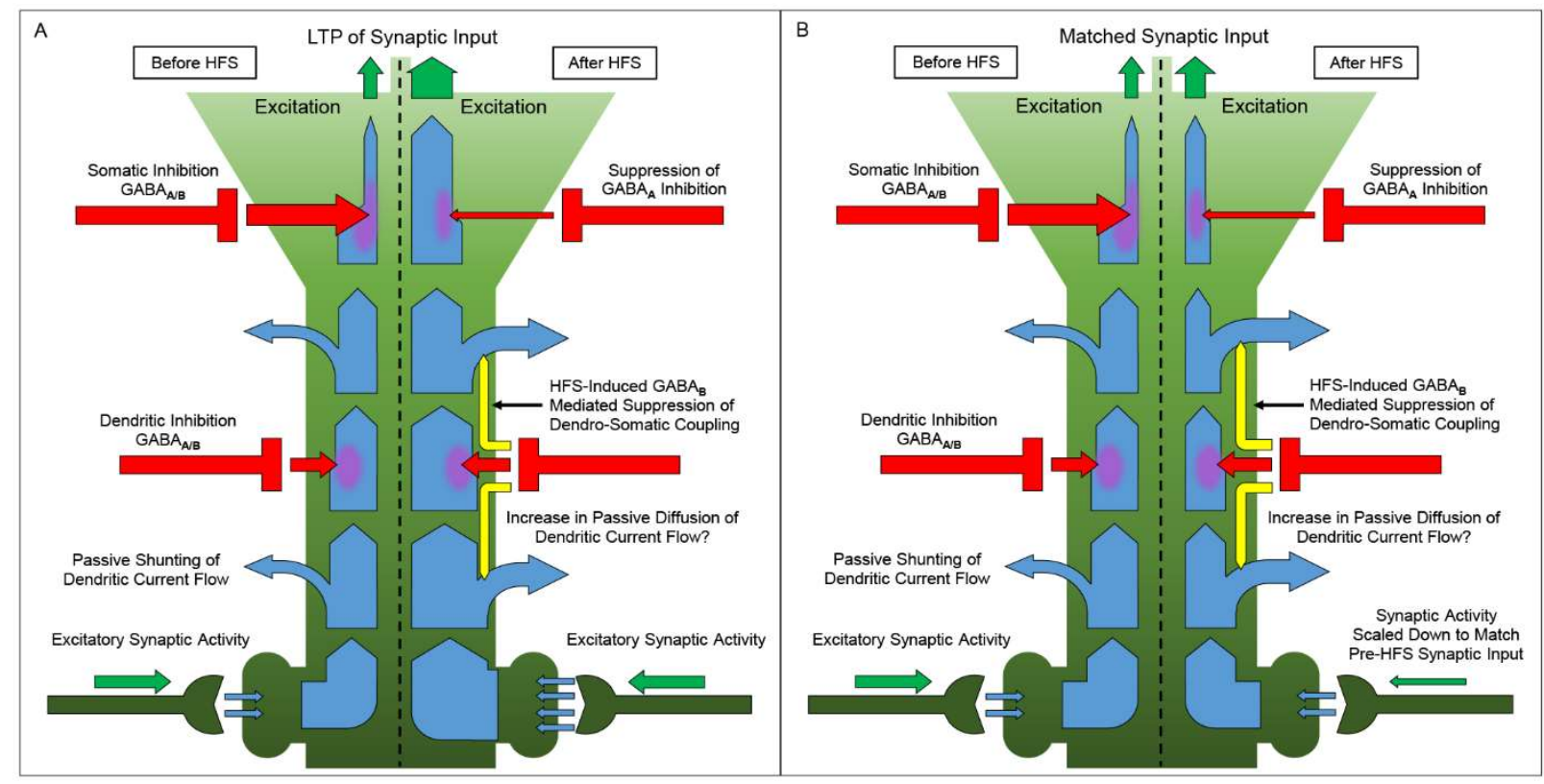


Figure 6: Changes in Dendro-Somatic electrical coupling accompany EPSP-Spike potentiation after HFS. Schematic illustrating the change in electrical coupling along the dendritic tree after HFS as excitatory current moves from synapses to soma, and the accompanying increase in excitability when this current reaches the spike trigger zone. Before HFS, excitatory synaptic current (blue arrows) is shunted along the dendritic tree as it moves from synapses to soma by passive dendritic current loss (blue arrows pointing outward), as well as blunting by GABAergic transmission (red arrows). The majority of inhibition however, occurs in and around the soma, and is largely driven by $\mathrm{GABA}_{A}$ transmission. $\mathrm{GABA}_{B}$ receptor activation during HFS produces an increase in electrical shunting through an unknown mechanism (yellow arrows) that persists after $\mathrm{HFS}$, and is not dependent on $\mathrm{GABA}_{B}$ transmission for the expression and maintenance of this change. This occurs in conjunction with a suppression of GABAA mediated inhibition in the soma, which allows for more current to reach the spike trigger zone, and results in an increase in excitability despite the reduction in D-S electrical coupling. A mechanism such as this may allow for regulating excitatory/inhibitory balance as a result of increased synaptic input and suppression of inhibition in the soma. A. Illustration of D-S coupling before and after HFS, where HFS produces an increase in excitatory synaptic transmission (LTP), along with an increase in electrical shunting as current moves up the dendrite to the soma. More current reaching the soma, in conjunction with a suppression of $\mathrm{GABA}_{\mathrm{A}}$ mediated inhibition in the soma, results in greater excitability. B. Illustration of D-S coupling before and after HFS, where synaptic input after HFS has been scaled down to match synaptic input before HFS. After HFS, there is more electrical shunting, and less current reaching the soma compared to 
before HFS. However, due to a substantial suppression of GABAA mediated inhibition in the soma, more current reaches the spike trigger zone, allowing for greater excitability compared to before HFS, and demonstrating the expression of EPSP-Spike potentiation. 